\title{
Species Lists in Ecology and Conservation: Abundances
}

\section{Matter}

Running head: Abundances matter in species lists

\section{Oliver Balmer}

Department of Ecology and Evolutionary Biology, Yale University, Osborn Memorial Laboratory, P.O. Box

208106, New Haven, CT 06520-8106, USA, email: oliver.balmer@yale.edu

and

Departement für Integrative Biologie, Universität Basel, Rheinsprung 9, 4051 Basel, Switzerland

Address for correspondence:

Oliver Balmer, Department of Ecology and Evolutionary Biology, Yale University, Osborn Memorial

Laboratory, P.O. Box 208106, New Haven, CT 06520-8106, USA, email: oliver.balmer@yale.edu

Word count: 780 
In the October 2001 issue of Conservation Biology, Gómez de Silva \& Medellín (2001) published an article on the problem of incomplete species lists in conservation and macroecology. They based their study on the observation that "studies of species diversity, macroecology, and conservation are usually based on lists of species, but lists found in the scientific literature vary in completeness". They concluded that "realistic results may be produced in macroecological and conservation studies only if they are based on reasonably complete species lists.” Here, I make the point, that there is an even more fundamental issue with respect to species lists that is in fact known, but whose effects are increasingly underestimated, especially in conservation: even complete species lists may fail to produce realistic results, and thus lead to wrong decisions, if they do not include estimates of the relative abundances of the species.

In ecology and conservation, conclusions or management decisions are often based on comparisons of species occurrences in different habitats or locations. This, in turn, is based on the assumption that species lists reflect the ecological character and value of different places and that such comparisons thus reveal real similarity or distinctness. Using data from Balmer (1999) and Balmer \& Erhardt (2000), I demonstrate that these assumptions may not hold if species frequencies are not accounted for.

I compared the butterfly assemblages on 12 pastures which were classified into three groups (denoted 1-3 in Fig. 1) based on vegetation type. I censused one standardized plot on each pasture over an entire season. Additionally, on two pastures (denoted 1B and 1N), a second plot was censused in close proximity to the first one. Thus 14 plots were censused. Because all pastures were homogeneous units, it is a safe assumption that two plots on the same pasture are ecologically very similar. I performed UPGMA cluster analyses, using both a similarity index that accounts for relative species abundances (Renkonen index), and one based only on the presence or absence of species (Sørensen index). Renkonen (= percentage) similarity index is calculated as $S_{R}=\sum\left(\operatorname{minimum}\left[p_{1 i}, p_{2 i}\right]\right)$, where $p_{1 i}=$ frequency of species $i$ in collection 1, and $p_{2 i}=$ frequency of species $i$ in collection 2 . Sørensen similarity index is calculated as $S_{S}=2 a /(2 a+b+c)$, where $a=$ number of shared species, $b=$ number of species only in collection 1 , and $c=$ number of species only in collection 2. See Krebs (1998) for details on methods and indices. Only the first analysis recovered the similarities of plots within $1 \mathrm{~B}$ and $1 \mathrm{~N}$ (Fig. 1). Comparisons of other available indices gave the same results. The most straightforward conclusion is that analyses which do not include the species’ relative abundances do not reveal the real ecological patterns in the data. 
The following hypothetical example may help strengthen the point. Figure 2 shows three species distributions about which we can ask, which two are most similar to one another. If we look only at what species are present, as is done with a presence-absence species list, A and B are identical and C is different. If we include the information on relative abundances, however, we see a clear pattern in the relative abundance of different species. It is obvious that, from an ecological perspective, A and C are the most similar. If we are to make comparisons of sites that are ecologically meaningful, therefore, we have to include the abundance information in this example. Only if the relative abundance distributions were equal across the plots, would both analyses yield the same conclusions. It is clear that species lists are better than no lists, and that relative abundances are better than simple lists (and that frequency dynamics are better than relative abundances). The question is, when can we afford to neglect one level of information.

When relying on data from the literature, estimates of abundance may not be available. However, if we want to claim that conclusions and decisions reflect real ecological patterns, we have to include at least rough estimates of species frequencies. We must be very clear that without estimation of the relative abundances, even results based on complete species lists may have little ecological meaning and lead to inappropriate conclusions and management decisions.

\section{Literature Cited}

Balmer, O. 1999. Die Schmetterlingsfauna an mageren Standorten des Jura in verschiedenen Stadien der Verbrachung. Mitteilungen der Schweizerischen Entomologischen Gesellschaft 72: 303-314.

Balmer, O. and Erhardt, A. 2000. Consequences of succession on extensively grazed grasslands for Central European butterfly communities: Rethinking conservation practices. Conservation Biology 14 (3): 746757.

Gómez de Silva, H. and R. A. Medellín. 2001. Evaluating completeness of species lists for conservation and macroecology: a case study of Mexican land birds. Conservation Biology 15:1384-1395.

Krebs, C. J. 1998. Ecological methodology. Benjamin / Cummings.

\section{[..Appendix omitted..]}




\section{Figure legends}

Figure 1. Dendrograms of UPGMA cluster analysis using Sørensen similarity index (left), and Renkonen (= percentage) similarity index (right). [..text omitted..] Plots of sites 1B and 1N highlighted. 1-3 are vegetation types, plot identities omitted (adapted from Balmer 1999).

Figure 2. Hypothetical abundance distributions for 10 species on 3 different sites A-C. 


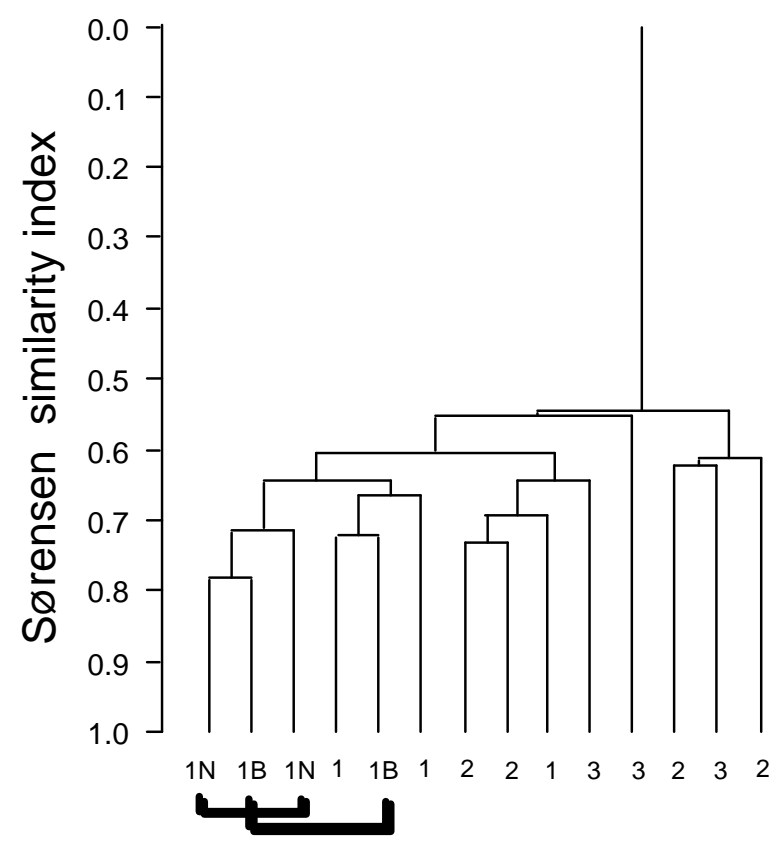

Sampled p lot

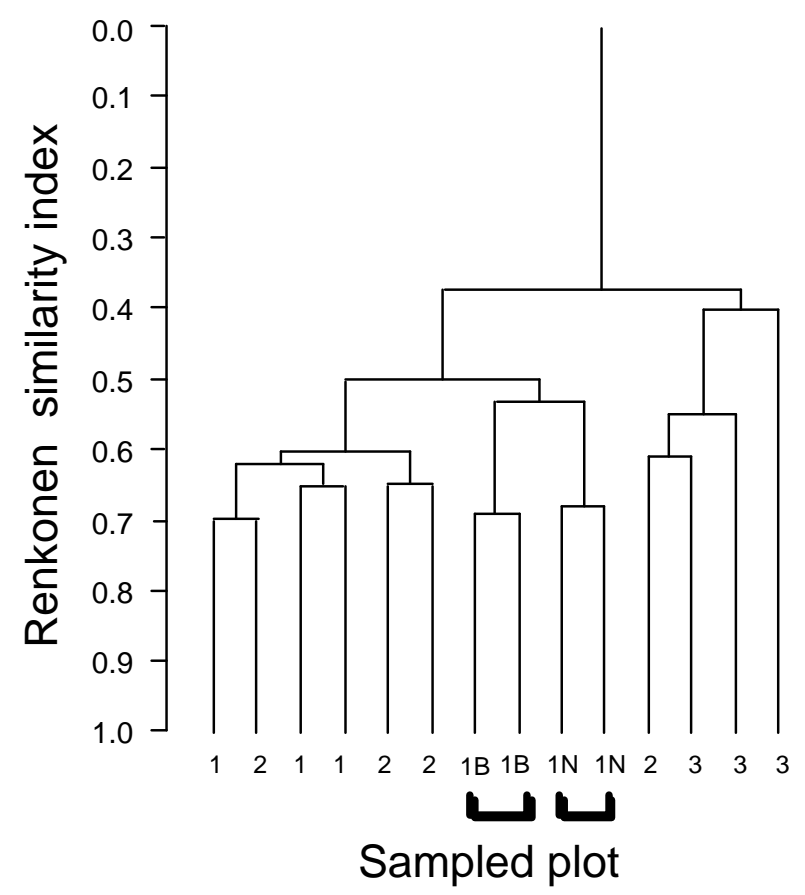

Figure 1

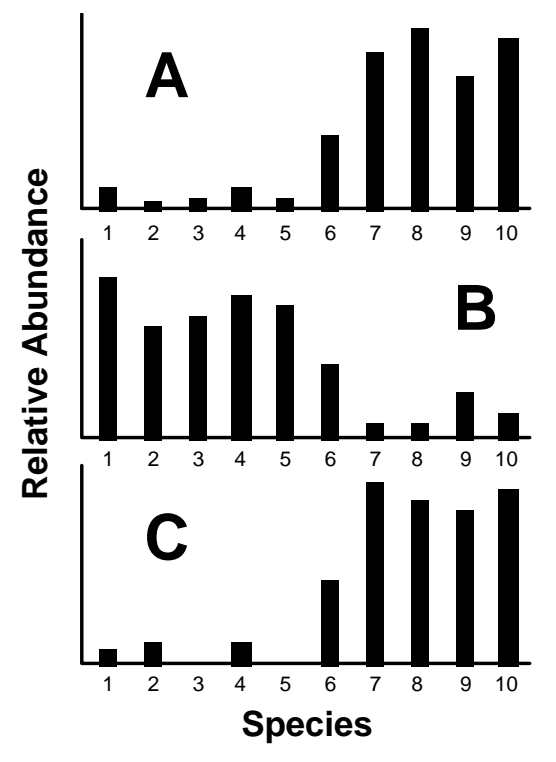

Figure 2 